\section{A 迎ecturue}

ON

\section{DISEASES OF THE HEART IN THE BRITISH ARMY: \\ THE CAUSE AND THE REMEDY.}

BY

W. C. MACLEAN, M.D.,

DEPUTY INSPECTOR-GENERAL; PROFESSOR OF MILITARY MEDICINE, ARMY MEVICAL SCHOOL, ETC.

Gentlemen, - Our last three morning meetings were devoted to the consideration of Pulmonary Consumption, viewed as a disease of military life. I entered fully into all the supposed causes, predisposing and exciting, and showed you that, notwithstanding all the improvements in the soldier's condition, the root of the evil has not yet been reached.

I dwelt particularly on the fact that, almost all over the world, the recommendations of the Barrack Commissioners, on the all-important point of space and ventilation in barracks, have not yet been carried out in anything like their integrity; that, in many of our garrisons, at home and abroad, the soldier has still only four hundred and fifty cubic feet and forty superficial feet per man. Even when the amount of cubic feet is in excess of the amount allowed by regulation, the air is imperfectly renewed in a great many of our barrack-rooms, from want of care in the ventilating arrangements. The result is the same in both cases-impure air, with its invariable concomitant, the prevalence of pulmonary consumption.

I touched also on the bad influence exerted by the knapsack and system of accoutrements in use in the army; and promised to go into this matter in more detail when I came to the subject of the present lecture ; viz., the Cause of Heart-Diseases in the Army.

And, first, are diseases of the heart and great vessels more prevalent in the army than in civil life? I think so.

I have often told you, that it is one of the drawbacks to our regimental system that some of our medical officers, until they come to do duty in such an hospital as this, are often imperfectly impressed with the real extent to which certain diseases prevail in the army. They see a certain limited number of cases, year after year, in their regimental hospitals, and, forgetting to multiply these by the number of battalions, they have no adequate knowledge of the extent to which certain diseases prevail, or the losses which the state suffers in men and money from them. It is only when they come to do duty in such an establishment as this (the Royal Victoria Hospital, Netley), where invalids from all parts of the world pass in review before us, that the eyes of many are opened. Many excellent and experienced staff-surgeons, who have served in all parts of the world, have expressed their astonishment to me on seeing for the first time the sad procession through our wards of so many men in every stage of phthisis and heart-disease; too many of them as clearly traceable to a remediable cause, as a case of inflamed eye to a visible particle of dust on its surface.

The hospital opened March 9th, 1863. From that date to the present month, December 1866, $5500 \mathrm{pa}$ tients passed through the Medical Division. 492 of the above were admitted for diseases of the heart; the great majority being men in the prime of life. Of these, 463 were lost to the service-that is, invalided.

This is only a part of the truth. I cannot tell you how many men, invalided from the Surgical Division, had heart-affection, that would, even had there been no surgical disability, have made them unfit for duty. Nor can I tell you how many men discharged from what we here call the Convalescent Division (the side of the house in which men about to be invalided, but requiring no medical treatment, are quartered) suffered in this way; but I do not doubt that the number was considerable. Nor must I forget to remind you that, in this hospital, we only see invalids from foreign stations. We know nothing here of the invaliding of men from home stations. But I can tell you that, when this school was located in Fort Pitt, and when invalids from the various districts and commands in Great Britain were sent there to be disposed of, I myself saw, between July 12th, 1860, and June 30th, 1861, 2769 men discharged the service. Of these, 445 (or 16.07 per cent.) were under two years' service; and, of the 445 lads thus discharged, heart-diseases made up 13.7 per cent. From Jnly 1st, 1861, to June 30th, 1862, 4087 men were discharged the service; 569 of them (or 13.92 per cent.) had less than two years' service; and of these, 14.76 per cent. were lost to the service from heart-diseases.

But even this is not the whole truth. The above figures tell us nothing about the Royal Artillery, the Household Troops, or that large portion of the British army quartered in Ireland.

Surely, I have said enough to awaken your attention. Let us now inquire into the cause or causes of all this suffering, costly invaliding, and inefficiency, with a view to the adoption of a remedy.

The return I hold in my hand shows that, out of the total admissions already given, 252 of our patients were entered as cases of valvular disease. Now, as I have often pointed out to you in the wards, the great majority of these men had none of the signs of valvular disease at all. No murmurs! Why is this? The official nomenclature in use in the service has no heading under which to include what may be called "irritable heart"- that rapid, often tumultuous action so common among scldiers; and, which, once established, is never got rid of so long as a man remains in the army and wears the dress and accoutrements of the infantry soldier. Such cases we are obliged to group either under the head of Morb. Valv. Cord. or Hypertrop. Cord.

Again, I have often pointed out to you that nothing is more common, than to see cases here of well-marked hypertrophy of the heart without valvular disease. The obstacle is not at the outlets of the heart's chambers; it is one which interferes with the free and healthy play of the organ. Look at this preparation. Mark this remarkable white spot on the external surface of this heart. It is as large, you see, as a five-shilling piece. What is it? Nothing, apparently, but a substance analogous to a corn; as much the result of friction and undue pressure, as are the torturing corns with which we are afflicted by unskilful boot-makers. We call it here "the soldier's spot", so common is it on the hearts of soldiers at our post mortem examinations. With this hypertrophy, there is almost always dilatation. In cases of long-standing, this leads to valvalar derangement, giving rise to murmurs. This is the history of that large number of cases in which we have distinct cardiac murmurs, with no history of rheumatism, acute or more chronic, to account for them.

Now, how can we account for the occurrence of 
this large amount of heart-disease? How far can we trace it to rheumatism? Out of all our cases only seven had a distinct history of pericarditis, three of carditis, and one of endocarditis ; and, although rheumatism-" the pains" - is of all diseases the most commonly complained of in the army, a vast number of our young men discharged the service had no history of rheumatism at all. Can we trace it to intemperance, particularly in cases of irritable heart? We must give the same reply. Intemperance is common, too common, among soldiers; but a large proportion of our young men are lost to the service ere they have contracted the baneful habit of spirit-drinking. It has been attributed to excessive smoking; but is there any evidence that soldiers smoke more than people of the same class in civil life? Certainly not. Neither have we any reliable facts to show that the use of tobacco, even to excess, can account for even one of the various forms of heart-disease, functional or organic, for which we are obliged to discharge so many of our soldiers of all ages.

Is it that soldiers are called upon to make greater exertions than the labouring and manufacturing classes? When I brought the subject of the present system of accoutreing the army before a meeting of the Royal United Service Institution, I put the same question, and replied to it thus: "Doubtless the soldier has, at drills, marches, and field-days, to put forth considerable exertion; but is this more, or so much, as we see daily dane by our navvies and others of the labouring classes? I think not. We must look, then, to the different conditions under which the two classes work. A labouring man or mechanic, when he addresses himself to his work, lays aside every weight and every article of dress that can in the slightest degree interfere with the free movement of his chest and limbs. In like manner, the sportsman or Alpine tourist adapts his dress to the work in which he is engaged. But the soldier, on the other hand, has to make the severest exertion at the utmost possible disadvantage, as regards the weight he has to carry, the mode in which he has to carry it, and the entire arrangement of his dress and equipment."

[The lecturer then reminded his hearers of the mechanism of respiration, going over all the alterations in form which the chest undergoes during inspiration and expiration, illustrating the demonstration by drawings.]

Is there anything in the mode in which the soldier is weighted and accoutred likely to interfere with these natural movements, more or less at all times, and particularly when making severe exertions? You shall judge for yourselves. Here is a soldier fully accoutred in heavy marching order, strictly according to present regulations, dressed and accoutred as he would be if under orders for a march to meet the enemy. What does he carry? His clothes, great coat, field-kit, and canteen, with sixty rounds of ammunition and seventy-five caps, his havresack, bayonet, rifle, and sling, pack and straps, pouch, etc., weigh exactly forty-eight pounds five ounces and a quarter avoirdupois.

But, in addition to that, he has his rations for three days, his blanket, his water-bottle-making in all sixty pounds three ounces and a half. How does he carry all this? Look at him as he stands before you. The whole weight of the pack is thrown on the straps passing under the arms; mark how they press on the great vessels and nerves which you know to occupy the arm-pit. When this man has marched for a few hours, his hands and arms will swell, grow numb, and painful; and you will, in all probability, see a comrade pass his hand between the straps and the arm-pits, shake the pack, thus to give a few moments of ease, and to change the points of pressure; our friend here doing a like good turn to his neighbour. The pouch and caps, you see, are carried on the buff belt, well pipe-clayed, which runs diagonally across the chest. 'The bayonet and ball-bag are carried on the waist-belt. You see, therefore, that the belts are so disposed as to press most injuriously on the chest : the cross-belt, stretched by the great weight of the pouch, impedes the forward movement of the ribs; the waist-belt hinders the expansion of the inferior false ribs, which, as we have just seen, in the state of unrestricted movement, is very great; and the pack-straps press on important muscles, arteries, veins, and nerves, to a degree which only those who have carried the loaded pack can appreciate. The weight, especially when the greatcoat (as on the soldier before you) is strapped on, falls, to a great extent, without the line of the centre of gravity. A good deal of this most unnatural restraint is obvious enough to you as the man stands before you making no exertion. You can well imagine how impossible it must be to make severe exertion under so many disadvantages without suffering.

That the objections I have just offered are not theoretical, you have had ample evidence; first, in the statistics of heart-disease plainly traceable to this most injudicious system of constriction; and, secondly, you have heard, in the wards of this hospital, from the lips of many sufferers examined by me in your presence, how well aware the men are themselves that they have been disabled for life by "the belts." I can never forget the interest taken by the old soldiers who were in Fort Pitt at the time when Professor Parkes, myself and colleagues, and Major Dethon, were making careful trials of the different packs you see on the table before you. They crowded round the men on whom they were fitted; they examined and criticised the fittings; and with one voice gave their unasked testimony to the suffering they had endured while wearing the regulation pack and accoutrements.

Once more, then, before I dismiss this soldier, I ask you to look carefully to all the details to which I have invited your attention.

You will now see, if you did not before, what an important matter this is : that it does not, as I know many of you fancied, concern the combatant officer merely ; but that it has most important bearings on the health, efficiency, and even the life of the soldier. To the purely military officer this question of dress and accoutrements is all-important; and it is astonishing to me how little most military men think about it. Look again at this man buttoned up to his throat; his neck still enclosed by a stiff leather stock, notwithstanding all that has been said and written in condemnation of that most mischievous and cruel collar. Look how the man is overweighted; note, again, how the weights are disposed in direct opposition to every sound principle of mechanics. Let us suppose an army or a division, dressed and accoutred as this man is-in strict obedience, be it observed, to the very letter of the Regulations-was expected by a general in command to make a rapid march over broken and difficult ground, and to appear on the field at a critical moment, as did the Crown Prince of Prussia at Sadowa: could men hampered and overweighted as this man is accomplish their allotted part in such an operation? Without doubt, no. One of two things must happen. If they struggle on, they must make their appearance on the field in time only to witness and share in a disastrous defeat, or they must cast away all these encumbrances. In either case, the condemnation of the system would be complete. This is not an 
imaginary case. When the British province of Canada was lately the scene of a marauding expedition from the American frontier, the greater part of the invaders escaped unpunished. Why? The regular soldiers were so overweighted that, although eager to meet the enemy, they were "too late". I mention this on high authority. I saw it in the handwriting of an officer on the spot, than whom no man living is more capable of speaking with authority on such a point.

But you will say these are military matters. Well, perhaps they are. But they are something more; they are matters of common sense and daily experience. I am myself a mountaineer born and bred, and am to this day accustomed to severe and prolonged exertion; but, if I were called upon to do a day's work on the moors in such a dress as the British soldier, in obedience to the traditions, not of the tield, but of the parade-ground, now wears, I should be in a state of degrading prostration in a few hours. But this is not all. Putting aside the remoter ill effects, in the shape of distressing heartdiseases, let me remind you of what I told you when on the subject of insolation. I saw the 98th Regiment disembark for active service before the enemy, in almost every particular accoutred and weighted like the man before you. In a few hours, fifteen or sixteen men were lying stiff and stark on the hillside, struck down, not by the enemy, but by the sun, powerfully aided by the obstruction to free respiration and circulation offered by their dress and accoutrements; while the 49 th and 18th Regiments, marching and fighting under the orders of officers more experienced in tropical service, with their jackets open, their throats free, no packs on their shoulders, hardly suffered at all.

This, at all events, is the subject from a medical point of view. But you are here training to be not merely medical men, but military surgeons and physicians. Your professional life is to be spent in caring for the soldier; and we, the professors in this school, are here to teach you the military bearings of such matters as we are now discussing.

But the British is not the only army that has suffered from a bad adjustment of the pack and accoutrements. The French and Prussian soldiers suffered in like manner; but some pains have been taken to find a remedy. The present mode of carrying the pack, both in the French and Prussian armies, although not perfect, is in every single particular superior to ours. Here they are. (The lecturer bere showed the French and Prussian packs; also those of Colonel Carter, Sir Thomas Trowbridge, Barrington's, and others; and minutely pointed out wherein the difference lay between them and the one in use in the British army, showing the absence of any cross-belt, the freedom from pressure on the armpits, the better distribution of the weights, and so on-at the same time pointing out defects, and expressing an opinion that in the best of them there is much room for improvement, and that the weight in all is too great. Some of the packs shown were peculiarly interesting, inasmuch as they were contrived by men who had themselves carried the British regulation knapsack, suffered in so doing; and, "knowing where the shoe pinched", had exerted their ingenuity to contrive something better.)

Is there any prospect of a remedy for this great evil? I am happy to say there is. Some result has followed the consideration given to this question in this school. A Committee of general and medical offlcers of experience is now investigating this matter, under the authority of the War Office and Horse Guards. My colleague Dr. Parkes is on this Com- mission, and mainly to his unwearied exertions the present hopeful prospect of a beneficial change is due. Dr. Parkes has not only done more than any one else to demonstrate the great mischief worked by the present system, but has brought a great deal of mechanical skill to bear in contriving a better system-one calculated to meet not merely the physiological, but the military, parts of the problem. He has laboured to satisfy the soldier as well as the doctor.

There is every reason to hope that the present knapsack and all its ill-contrived belongings will soon only be seen in our museum upstairs, among other curious examples of "how not to do it". Ere long our men will be rid of this encumbrance, which has long sat on their shoulders like the Old Man of the Sea on those of Sinbad the Sailor. When this comes to pass, those who succeed you on the benches you now occupy will, I am confident, have fewer opportunities of studying the affections of the heart of which you have seen and heard so much in this hospital; the efficiency of the service will be immensely promoted; and the British army will cease to throw out into the civil population every year a large number of men so organically damaged as to be unfit to earn their bread in any laborious occupation.

It may perhaps be said that, in time of peace, soldiers are not obliged to carry such a weight as the man did who was before you a few minutes ago. That is quite true. Nevertheless, it is certain that at no period of our history was the pack more worn than at present. I find that it is worn at least once a day on regimental parade, and on all brigade and field days, at all the camps in this kingdom. I have been at some pains to ascertain from regimental medical officers the effects observed on the men, particularly on field days. Some do not appear to have paid much attention to the subject, but the majority seem alive to the ill effects of the pack and accoutrements.

Many men fall out in a state of extreme distress; and many surgeons assure me that nothing but a strong feeling of esprit de corps prevents many more from doing so. In well-disciplined regiments, the practice of falling out at drill or on the line of march is discouraged. Men will suffer much rather than incur the imputation of being "soft". Some, to my own knowledge, have worked on through a field day, and have died rather than give in. An instance of this occurred at Aldershot on a field day about two years ago.

In the first of the reports on packs submitted for the consideration of the General Commanding at Chatham, by the professors of the Army Medical School, the following were the general principles insisted on.

1. To distribute the weight, as far as practicable, over the body.

2. To bring the weight, as far as possible, within the line of the centre of gravity.

3. To allow no pressure on the principal muscles, nerves, arteries, or veins.

4. To avoid most carefully all impediments to the fullest expansion of the lungs, and to the action of the heart. We insisted on this last as the cardinal rule of all; because, unless the circulation through the lungs be quite free, not only will continued exertion become impossible, but the structure of the heart must suffer. The commonest experience shows that the number of respirations and the amount of air drawn into and expired from the lungs is enormously increased by exertion. Late physiological inquiries have shown that the elimination of carbonic acid is also prodigiously augmented, and this 
is a necessary sequence of the muscular contraction. If this elimination be prevented by interference with respiration, no amount of energy or volition on the part of the man will enable him to continue his exertion.

I have shown you how immensely superior the Prussian pack and accoutrements are to ours. Yet the authorities there are determined to profit by the experience of the late war ; and a Commission is now reviewing the whole question, with a view to greater improvements; and, from what I have heard, unless we are early in the field with our improved system, I suspect the Prussian army will be soon accoutred on a plan as superior to the old as that was and is to the system still in force in the British army.

$=$

\section{THE

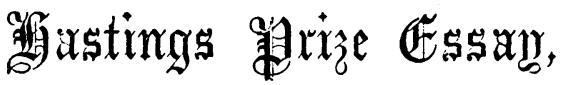

1866.

ON

\section{SHOCK AFTER SURGICAL OPERATIONS} AND INJURIES.*

BY

FURNEAUX JORDAN, F.R.C.S.ENG., SURGEON TO AND PROFESSOR OF CLINICAL SURGERY AT THE QUEEN'S HOSPITAL, BIRMINGHAM.

The Thermometer in Shock.

Is order to give greater precision to, and, if possible, to extend our knowledge of, the phenomena of shock, I have in numerous cases, a few of which I shall cite, made use of the thermometer by the axillary method, the advantages of which have been so ably enforced by Wunderlich. It was long a tenet in physiology, that variations in temperature affect the surface only; and that the blood, as a whole, remains unaltered. The researches of Wunderlich, Parkes, Simon, and others, have shown that in inflammation, in febrile and other conditions, a considerable elevation of temperature above the normal heat of the blood is undoubtedly experienced. The same observers have also arrived at the conclusion, that diminution in the temperature of the body is rare, and much less extensive in its range.

In several cases in which I have used the thermometer after severe operations, such as amputation of the thigh, the temperature has descended to $97^{\circ}$ Fahr., more commonily to $97^{\circ}$ and a few tenths; its descent below $97^{\circ}$ is rare. A few tenths of a degree only below $97^{\circ}$ appears to be compatible with life. A most interesting and striking fact, which I have found to occur in all amputations of the thigh, is this: that when the saw is applied to the bone, the moment it comes into action, the'temperature of the body suddenly falls a fifth of a degree, a little more or a little less. No change is seen when the soft parts are cut; and I have carefully investigated this

* Continued from page 197 of Jounxas for Feb. 9th. point by the use of the thermometer in many cases of amputation of the thigh-an operation in which the cut surfaces of the soft tissues are perhaps larger than in any other operation. That the thermometer should register a diminution in the temperature when the saw is dividing the bone, is most remarkable, because of its comparatively scanty supply of nerves; while the skin, so abundantly supplied with sentient or afferent nerves, gives rise, when cut with a knife, to no change in the temperature. The most probable explanation of this singular phenomenon is, the greater laceration of the nerves, smaller and fewer as they are, which instantaneously gives rise to shock, as indicated by depressed cardiac action and lowered temperature.

No change is seen in the thermometer on the administration of chloroform.

After the period of shock which immediately supervenes on a serious operation or injury, the temperature gradually rises, if the shock be not fatal, to a point above the normal standard corresponding to the degree of intensity of the fever of reaction. If the shock be fatal, the thermometer does not usually fall below $97^{\circ} \mathrm{Fahr}$. The fever of reaction, so far as I have been able to observe, differs from " medical" fevers in the temperature which it reaches prior a fatal termination. While ordinary fevers reach a temperature varying from $106^{\circ}$ to $110^{\circ}$ just before death, the fever of shock, under similar circumstances, reaches a temperature only of $100^{\circ}$ or $102^{\circ}$. Those cases of reaction are always the most dangerous in which the temperature keeps low, and especially at the early periods of fever.

I append a few cases in illustration of the several conclusions I have brought forward.

I shall give a tabular view of the cases, and comment upon them as I proceed. My observations, although mainly directed to the thermometric aspects of the cases, will extend to such other peculiarities as may seem to justify remark.

Tabular view of the case of Alice G., aged 22, showing the Temperature, and the condition of the Pulse and Respiration, just before, during, and at several periods shortly after, the operation of Resection of the Shoulder.

\begin{tabular}{|c|c|c|c|}
\hline & Pulse. & Respiration. & Temp. \\
\hline An hour prior to operation & 92 & & 98.8 \\
\hline Under chloroform $\ldots \ldots \ldots$ & 92 & Irregular & 98.8 \\
\hline Incision in soft parts ...... & 92 & Irregular & 98.8 \\
\hline Application of saw to bone & Suddeniy & Irregular & $\{98.8$ \\
\hline When bone divided ........ & 92 & Irregular & $\begin{array}{l}98.6 \\
98.8\end{array}$ \\
\hline Fifteeen minutes after oper- & 82 & 16 & 080 \\
\hline Six hours after operation .. & 108 & 2.2 & $\begin{array}{r}98.0 \\
102.0\end{array}$ \\
\hline Morning, second day ...... & 106 & 28 & 100.0 \\
\hline Fvening, second day ...... & 126 & 30 & 102.4 \\
\hline Morning, third day .... & 120 & 28 & 102.0 \\
\hline Evening, third day ... & 128 & 30 & 102.4 \\
\hline
\end{tabular}

This case reveals a very slight form of shock, the temperature of the body at no time descending below $98^{\circ}$ Fahrenheit. The sudden and momentary lowering of the temperature at the commencement of the sawing through the bone is very obvious. Reaction was rapid and sharp, and recovery favourable. The case was one of strumous osteitis affecting the head of the humerus, of three years' duration, numerous suppurating sinuses having been present for eighteen months. 